\title{
Fukui Function Analysis and Optical, Electronic, and Vibrational Properties of Tetrahydrofuran and Its Derivatives: A Complete Quantum Chemical Study
}

\author{
Apoorva Dwivedi, ${ }^{1}$ Vikas Baboo, ${ }^{2}$ and Abhishek Bajpai ${ }^{1}$ \\ ${ }^{1}$ Department of Physics, Govt. Kakatiya P. G. College Jagdalpur, Bastar, Chhattisgarh 494001, India \\ ${ }^{2}$ Department of Chemistry, Lucknow University, Lucknow, Uttar Pradesh 226007, India \\ Correspondence should be addressed to Abhishek Bajpai; abhi_bajpai1234@rediffmail.com
}

Received 10 September 2014; Revised 25 November 2014; Accepted 25 November 2014

Academic Editor: John R. Sabin

Copyright (C) 2015 Apoorva Dwivedi et al. This is an open access article distributed under the Creative Commons Attribution License, which permits unrestricted use, distribution, and reproduction in any medium, provided the original work is properly cited.

The spectroscopic, optical, and electronic properties of tetrahydrofuran and its derivatives were investigated by FTIR techniques. We have done a comparative study of tetrahydrofuran and its derivatives with B3LYP with 6-311 G $(\mathrm{d}, \mathrm{p})$ as the basis set. Here we have done a relative study of their structures, vibrational assignments, and thermal, electronic, and optical properties of ttetrahydrofuran and its derivatives. We have plotted frontier orbital HOMO-LUMO surfaces and molecular electrostatic potential surfaces to explain the reactive nature of tetrahydrofuran and its derivatives.

\section{Introduction}

Tetrahydrofuran (THF) is an organic compound with the formula $\left(\mathrm{CH}_{2}\right)_{4} \mathrm{O}$. The compound is classified as heterocyclic compound, specifically a cyclic ether. It is a colorless, watermiscible organic liquid with low viscosity. THF has an odor similar to acetone. Being polar and having a wide liquid range, THF is a versatile solvent. THF is often used in polymer science. For example, it can be used to dissolve polymers prior to determining their molecular mass using gel permeation chromatography. THF is also a starting material for the preparation of tetrahydrothiophene. In the presence of a solid acid catalyst, it reacts with hydrogen sulfide. THF is frequently utilized as a solvent in many pharmaceutical synthetic procedures because of its good solvency for polar and nonpolar compounds. THF is particularly capable of dissolving many ionic species and organometallics which are commonly used in specialty syntheses. In many cases, THF makes higher yields and faster reaction rates possible. In addition, THF's high volatility and very high purity facilitate solvent removal and recovery without leaving residues in the desired product $[1,2]$. Tetrahydrofuran (THF) is a synthesized organic compound that is not found in the natural environment. THF is highly flammable and upon thermal decomposition may form carbon monoxide and carbon dioxide. Under certain conditions, such as prolonged storage in contact with air, THF can decompose into explosive peroxides [3]. THF can also be synthesized by catalytic hydrogenation of furan $[4,5]$. THF has been explored as a water-based cosolvent to aid in the deconstruction and delignification of plant lignocellulosic biomass, which are relevant to the production of renewable platform chemicals and sugars. THF is used as a component in mobile phases for reversed-phase liquid chromatography. It has a greater elution strength than methanol or acetonitrile but is less commonly used than these solvents [6].

As a part of our ongoing research work [7-9], we report the comparative study of tetrahydrofuran (THF) and its derivatives by DFT study. To the best of our knowledge no comparative quantum chemical calculations of these molecules have been reported so far in the literature.

\section{Experimental and Computational Methods}

2.1. Structure and Spectra. The molecular structures of the tetrahydrofuran (THF) and its derivatives are made by molecular modeling. The model molecular structures of tetrahydrofuran (THF) and its derivatives are given in Figure 1. 


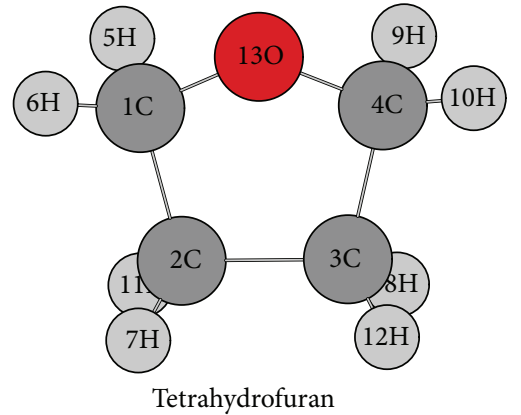

(a)

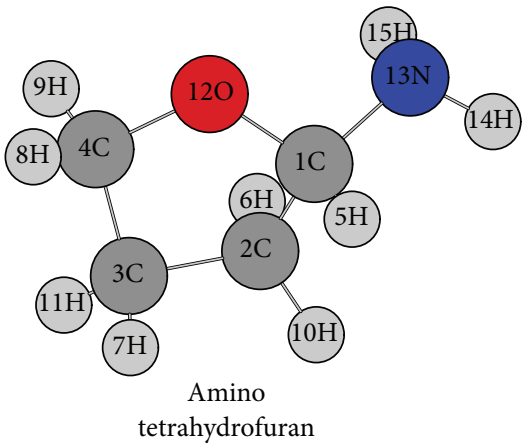

(b)

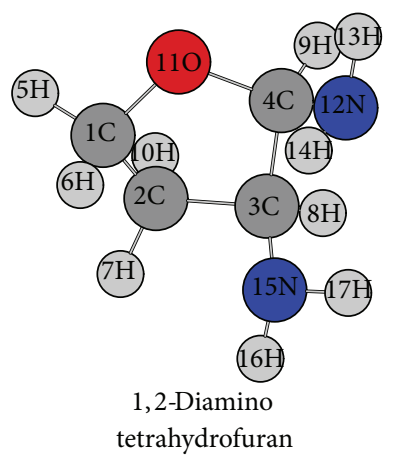

(c)

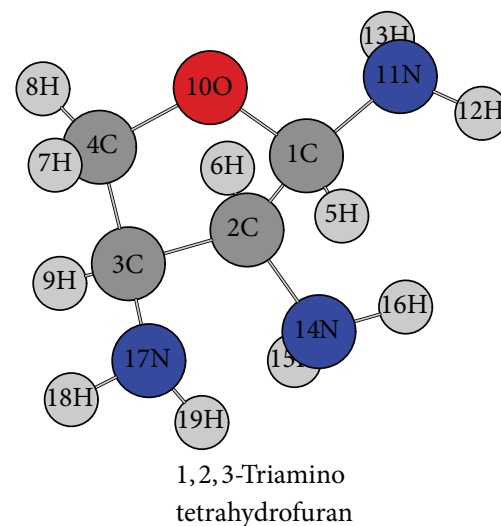

(d)

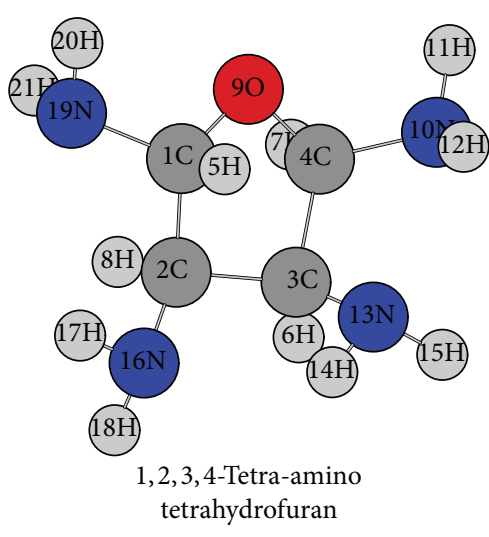

(e)

FIgURE 1: Model molecular structures of tetrahydrofuran and its derivatives.

We have taken the infrared spectrum of tetrahydrofuran (THF) from literature which was recorded with FTIR Perkin Elmer spectrometer in $\mathrm{KBr}$ dispersion in the range of 500 to $4000 \mathrm{~cm}^{-1}$ for the title molecule as shown in Figure 3 [10].

2.2. Computational Methods. All the calculations were performed by the B3LYP $[11,12]$ method using the $6-311 \mathrm{G}(\mathrm{d}, \mathrm{p})$ basis set of density functional theory [13]. All computations were carried out with the GAUSSIAN 09 package [14]. By combining the results of the GAUSSVIEW'S program [15] with symmetry considerations, vibrational frequency assignments were made with a high degree of accuracy. Vibrational frequencies for these molecules were calculated with these methods and then scaled by 0.9613 [16].

\section{Results and Discussion}

3.1. Geometry Optimization. Alternate dispositions of amino groups have been studied, but finally we get these five optimized structures of THF derivatives. Optimized parameters of tetrahydrofuran (THF) and its derivatives (amino tetrahydrofuran, 1,2-diamino tetrahydrofuran, 1,2,3-triamino tetrahydrofuran, and 1,2,3,4-tetra-amino tetrahydrofuran) calculated by B3LYP method with 6-311 G (d, p) basis set are listed in Table 1 in accordance with the atom numbering scheme as shown in Figure 1. Local minimum energies are -232.5134 a.u, -287.8832 a.u, -343.2555 a.u, -398.6109 a.u, and -453.9997 a.u., for tetrahydrofuran (THF), amino tetrahydrofuran, 1,2-diamino tetrahydrofuran, 1,2,3-triamino tetrahydrofuran, and 1,2,3,4-tetra-amino tetrahydrofuran, respectively. Tetrahydrofuran (THF) and all its derivatives have $C_{1}$ point group symmetry. The amino groups attached to all derivatives do not lie in the plane of ring and alternatively they are in the opposite direction to each other.

For tetrahydrofuran (THF) and its derivatives, $\mathrm{C}-\mathrm{C}$ bond distances are found to be in the range of $1.542-1.553 \AA$, $1.529-1.543 \AA, 1.529-1.552 \AA, 1.540-1.542 \AA$, and $1.532-1.549 \AA$ while, for $\mathrm{C}-\mathrm{N}$ (except THF), these values are $1.443 \AA, 1.438$ $1.467 \AA, 1.435-1.461 \AA$, and $1.428-1.462 \AA$, respectively, for amino tetrahydrofuran, 1,2-diamino tetrahydrofuran, 1,2,3triamino tetrahydrofuran, and 1,2,3,4-tetra-amino tetrahydrofuran. For C-O, these values are $1.423 \AA, 1.434 \AA$, $1.429 \AA$, $1.431 \AA$, and 1.435-1.462 $\AA$, respectively, for THF, amino tetrahydrofuran, 1,2-diamino tetrahydrofuran, 1,2,3-triamino tetrahydrofuran, and 1,2,3,4-tetra-amino tetrahydrofuran. In case of $\mathrm{C}-\mathrm{H}$ bond distances, they lie in the range of 1.091$1.101,1.093,1.092-1.094,1.097-1.102$, and 1.096-1.101, respectively. In the literature, bond lengths for THF-water complex [17] have a little bit lower values of 1.527-1.537 $\AA$ (for (C-C)) and a little bit higher values of $1.443-1.446 \AA$ (for (C-O)). This may be due to shifting of charge in interaction of THF with water molecule. Optimized structures of tetrahydrofuran and its derivatives by B3LYP/6-311 G $(d, p)$ method are shown in Figure 1. 
TABLE 1: Optimized geometrical parameters of tetrahydrofuran and its derivatives by B3LYP/6-311 G (d, p) method.

\begin{tabular}{|c|c|c|c|c|c|c|c|c|c|}
\hline \multicolumn{2}{|c|}{ THF } & \multicolumn{2}{|c|}{ Amino THF } & \multicolumn{2}{|c|}{ 1,2-Diamino THF } & \multicolumn{2}{|c|}{ 1,2,3-Triamino THF } & \multicolumn{2}{|c|}{ 1,2,3,4-Tetra-amino THF } \\
\hline Parameters & $\begin{array}{c}\text { 6-311 G } \\
(\mathrm{d}, \mathrm{p})\end{array}$ & Parameters & $\begin{array}{c}\text { 6-311 G } \\
(\mathrm{d}, \mathrm{p})\end{array}$ & Parameters & $\begin{array}{c}\text { 6-311 G } \\
(\mathrm{d}, \mathrm{p})\end{array}$ & Parameters & $\begin{array}{c}\text { 6-311 G } \\
(\mathrm{d}, \mathrm{p})\end{array}$ & Parameters & $\begin{array}{c}\text { 6-311 G } \\
(\mathrm{d}, \mathrm{p})\end{array}$ \\
\hline$R(1,2)$ & 1.5432 & $R(1,2)$ & 1.5418 & $R(1,2)$ & 1.5292 & $R(1,2)$ & 1.5423 & $R(1,2)$ & 1.5325 \\
\hline$R(1,5)$ & 1.1011 & $R(1,5)$ & 1.0999 & $R(1,5)$ & 1.0924 & $R(1,5)$ & 1.097 & $R(1,5)$ & 1.0961 \\
\hline$R(1,6)$ & 1.0906 & $R(1,12)$ & 1.4347 & $R(1,6)$ & 1.0965 & $R(1,10)$ & 1.431 & $R(1,9)$ & 1.4353 \\
\hline$R(1,13)$ & 1.4235 & $R(1,13)$ & 1.4439 & $R(1,11)$ & 1.4291 & $R(1,11)$ & 1.4351 & $R(1,19)$ & 1.437 \\
\hline$R(2,3)$ & 1.5535 & $R(2,3)$ & 1.5295 & $R(2,3)$ & 1.5337 & $R(2,3)$ & 1.538 & $R(2,3)$ & 1.5383 \\
\hline$R(2,7)$ & 1.0915 & $R(2,6)$ & 1.0962 & $R(2,7)$ & 1.093 & $R(2,6)$ & 1.1027 & $R(2,8)$ & 1.1019 \\
\hline$R(2,11)$ & 1.0918 & $R(2,10)$ & 1.0923 & $R(2,10)$ & 1.0939 & $R(2,14)$ & 1.46 & $R(2,16)$ & 1.4594 \\
\hline$R(3,4)$ & 1.5422 & $R(3,4)$ & 1.5356 & $R(3,4)$ & 1.5521 & $R(3,4)$ & 1.54 & $R(3,4)$ & 1.5497 \\
\hline$R(3,8)$ & 1.0918 & $R(3,7)$ & 1.0942 & $R(3,8)$ & 1.0989 & $R(3,9)$ & 1.1016 & $R(3,6)$ & 1.0984 \\
\hline$R(3,12)$ & 1.0915 & $R(3,11)$ & 1.092 & $R(3,15)$ & 1.4672 & $R(3,17)$ & 1.4619 & $R(3,13)$ & 1.462 \\
\hline$R(4,9)$ & 1.1012 & $R(4,8)$ & 1.0935 & $R(4,9)$ & 1.0945 & $R(4,7)$ & 1.094 & $R(4,7)$ & 1.0951 \\
\hline$R(4,10)$ & 1.0906 & $R(4,9)$ & 1.0978 & $R(4,11)$ & 1.4492 & $R(4,8)$ & 1.097 & $R(4,9)$ & 1.4623 \\
\hline$R(4,13)$ & 1.4233 & $R(4,12)$ & 1.4316 & $R(4,12)$ & 1.4383 & $R(4,10)$ & 1.4345 & $R(4,10)$ & 1.4288 \\
\hline$A(2,1,5)$ & 110.59 & $R(13,14)$ & 1.0139 & $R(12,13)$ & 1.0140 & $R(11,12)$ & 1.0099 & $R(10,11)$ & 1.0139 \\
\hline$A(2,1,6)$ & 114.00 & $R(13,15)$ & 1.0156 & $R(12,14)$ & 1.0161 & $R(11,13)$ & 1.013 & $R(10,12)$ & 1.0164 \\
\hline$A(2,1,13)$ & 105.68 & $A(2,1,5)$ & 109.82 & $R(15,16)$ & 1.0146 & $R(14,15)$ & 1.0148 & $R(13,14)$ & 1.0168 \\
\hline$A(5,1,6)$ & 108.53 & $A(2,1,12)$ & 104.71 & $R(15,17)$ & 1.0158 & $R(14,16)$ & 1.016 & $R(13,15)$ & 1.0126 \\
\hline$A(5,1,13)$ & 110.07 & $A(2,1,13)$ & 118.27 & $A(2,1,5)$ & 113.45 & $R(17,18)$ & 1.0134 & $R(16,17)$ & 1.0166 \\
\hline$A(6,1,13)$ & 107.85 & $A(5,1,12)$ & 108.94 & $A(2,1,6)$ & 110.73 & $R(17,19)$ & 1.0163 & $R(16,18)$ & 1.0149 \\
\hline$A(1,2,3)$ & 103.35 & $A(5,1,13)$ & 106.64 & $A(2,1,11)$ & 104.92 & $A(2,1,5)$ & 108.92 & $R(19,20)$ & 1.0145 \\
\hline$A(1,2,7)$ & 110.79 & $A(12,1,13)$ & 108.17 & $A(5,1,6)$ & 108.92 & $A(2,1,10)$ & 103.40 & $R(19,21)$ & 1.017 \\
\hline$A(1,2,11)$ & 111.71 & $A(1,2,3)$ & 102.64 & $A(5,1,11)$ & 108.20 & $A(2,1,11)$ & 117.42 & $A(2,1,5)$ & 109.37 \\
\hline$A(3,2,7)$ & 110.69 & $A(1,2,6)$ & 109.05 & $A(6,1,11)$ & 110.49 & $A(5,1,10)$ & 110.09 & $A(2,1,9)$ & 104.13 \\
\hline$A(3,2,11)$ & 112.63 & $A(1,2,10)$ & 112.24 & $A(1,2,3)$ & 102.05 & $A(5,1,11)$ & 107.87 & $A(2,1,19)$ & 112.24 \\
\hline$A(7,2,11)$ & 107.66 & $A(3,2,6)$ & 110.68 & $A(1,2,7)$ & 113.41 & $A(10,1,11)$ & 108.98 & $A(5,1,9)$ & 109.70 \\
\hline$A(2,3,4)$ & 103.31 & $A(3,2,10)$ & 114.04 & $A(1,2,10)$ & 110.29 & $A(1,2,3)$ & 101.55 & $A(5,1,19)$ & 107.76 \\
\hline$A(2,3,8)$ & 112.69 & $A(6,2,10)$ & 108.04 & $A(3,2,7)$ & 112.77 & $A(1,2,6)$ & 106.59 & $A(9,1,19)$ & 113.54 \\
\hline$A(2,3,12)$ & 110.65 & $A(2,3,4)$ & 101.29 & $A(3,2,10)$ & 109.88 & $A(1,2,14)$ & 112.73 & $A(1,2,3)$ & 101.74 \\
\hline$A(4,3,8)$ & 111.81 & $A(2,3,7)$ & 110.39 & $A(7,2,10)$ & 108.30 & $A(3,2,6)$ & 107.83 & $A(1,2,8)$ & 106.95 \\
\hline$A(4,3,12)$ & 110.69 & $A(2,3,11)$ & 113.81 & $A(2,3,4)$ & 102.30 & $A(3,2,14)$ & 114.08 & $A(1,2,16)$ & 111.71 \\
\hline$A(8,3,12)$ & 107.68 & $A(4,3,7)$ & 110.55 & $A(2,3,8)$ & 111.46 & $A(6,2,14)$ & 113.14 & $A(3,2,8)$ & 107.89 \\
\hline$A(3,4,9)$ & 110.60 & $A(4,3,11)$ & 112.78 & $A(2,3,15)$ & 110.20 & $A(2,3,4)$ & 100.24 & $A(3,2,16)$ & 114.45 \\
\hline$A(3,4,10)$ & 114.02 & $A(7,3,11)$ & 107.93 & $A(4,3,8)$ & 109.35 & $A(2,3,9)$ & 111.23 & $A(8,2,16)$ & 113.21 \\
\hline$A(3,4,13)$ & 105.58 & $A(3,4,8)$ & 112.97 & $A(4,3,15)$ & 109.78 & $A(2,3,17)$ & 109.07 & $A(2,3,4)$ & 101.38 \\
\hline$A(9,4,10)$ & 108.54 & $A(3,4,9)$ & 111.11 & $A(8,3,15)$ & 113.16 & $A(4,3,9)$ & 110.64 & $A(2,3,6)$ & 111.63 \\
\hline$A(9,4,13)$ & 110.10 & $A(3,4,12)$ & 106.54 & $A(3,4,9)$ & 110.01 & $A(4,3,17)$ & 110.92 & $A(2,3,13)$ & 109.53 \\
\hline$A(10,4,13)$ & 107.87 & $A(8,4,9)$ & 108.09 & $A(3,4,11)$ & 106.27 & $A(9,3,17)$ & 113.88 & $A(4,3,6)$ & 109.58 \\
\hline$A(1,13,4)$ & 105.45 & $A(8,4,12)$ & 108.85 & $A(3,4,12)$ & 112.46 & $A(3,4,7)$ & 110.82 & $A(4,3,13)$ & 110.85 \\
\hline - & - & $A(9,4,12)$ & 109.18 & $A(9,4,11)$ & 106.73 & $A(3,4,8)$ & 111.61 & $A(6,3,13)$ & 113.23 \\
\hline - & - & $A(1,12,4)$ & 110.98 & $A(9,4,12)$ & 107.64 & $A(3,4,10)$ & 107.36 & $A(3,4,7)$ & 110.69 \\
\hline- & - & $A(1,13,14)$ & 110.92 & $A(11,4,12)$ & 113.55 & $A(7,4,8)$ & 108.85 & $A(3,4,9)$ & 105.55 \\
\hline - & - & $A(1,13,15)$ & 110.93 & $A(1,11,4)$ & 110.13 & $A(7,4,10)$ & 109.52 & $A(3,4,10)$ & 111.81 \\
\hline - & - & - & - & $A(4,12,13)$ & 110.02 & $A(8,4,10)$ & 108.62 & $A(7,4,9)$ & 106.37 \\
\hline - & - & - & - & $A(4,12,14)$ & 109.06 & $A(1,10,4)$ & 109.9819 & $A(7,4,10)$ & 108.40 \\
\hline - & - & - & - & $A(13,12,14)$ & 107.59 & $A(1,11,12)$ & 113.46 & $A(9,4,10)$ & 113.85 \\
\hline
\end{tabular}


TABle 1: Continued.

\begin{tabular}{|c|c|c|c|c|c|c|c|c|c|}
\hline \multicolumn{2}{|c|}{ THF } & \multicolumn{2}{|c|}{ Amino THF } & \multicolumn{2}{|c|}{ 1,2-Diamino THF } & \multicolumn{2}{|c|}{ 1,2,3-Triamino THF } & \multicolumn{2}{|c|}{ 1,2,3,4-Tetra-amino THF } \\
\hline Parameters & $\begin{array}{c}\text { 6-311 G } \\
(\mathrm{d}, \mathrm{p})\end{array}$ & Parameters & $\begin{array}{c}\text { 6-311 G } \\
(\mathrm{d}, \mathrm{p})\end{array}$ & Parameters & $\begin{array}{c}\text { 6-311 G } \\
(\mathrm{d}, \mathrm{p})\end{array}$ & Parameters & $\begin{array}{c}\text { 6-311 G } \\
(\mathrm{d}, \mathrm{p})\end{array}$ & Parameters & $\begin{array}{c}\text { 6-311 G } \\
(\mathrm{d}, \mathrm{p})\end{array}$ \\
\hline - & - & - & - & $A(3,15,16)$ & 109.93 & $A(1,11,12)$ & 113.46 & $A(1,9,4)$ & 110.34 \\
\hline - & - & - & - & $A(3,15,17)$ & 109.19 & $A(1,11,13)$ & 113.56 & $A(4,10,11)$ & 110.56 \\
\hline - & - & - & - & $A(16,15,17)$ & 107.21 & $A(12,11,13)$ & 111.02 & $A(4,10,12)$ & 108.57 \\
\hline- & - & - & - & - & - & $A(2,14,15)$ & 110.84 & $A(11,10,12)$ & 108.78 \\
\hline - & - & - & - & - & - & $A(2,14,16)$ & 109.77 & $A(3,13,14)$ & 108.28 \\
\hline - & - & - & - & - & - & $A(15,14,16)$ & 106.59 & $A(3,13,15)$ & 110.98 \\
\hline - & - & - & - & - & - & $A(3,17,18)$ & 111.18 & $A(14,13,15)$ & 109.23 \\
\hline - & - & - & - & - & - & $A(3,17,19)$ & 108.87 & $A(2,16,17)$ & 108.48 \\
\hline - & - & - & - & - & - & $A(18,17,19)$ & 108.95 & $A(2,16,18)$ & 110.81 \\
\hline - & - & - & - & - & - & - & - & $A(17,16,18)$ & 106.92 \\
\hline - & - & - & - & - & - & - & - & $A(1,19,20)$ & 110.63 \\
\hline - & - & - & - & - & - & - & - & $A(1,19,21)$ & 109.69 \\
\hline- & - & - & - & - & - & - & - & $A(20,19,21)$ & 107.19 \\
\hline
\end{tabular}

TABLE 2: Vibrational assignments of tetrahydrofuran (modes having high IR intensity only) with B3LYP/6-311 G (d, p).

\begin{tabular}{|c|c|c|c|c|c|}
\hline $\begin{array}{l}\text { B3LYP (calculated) } \\
\text { unscaled }\end{array}$ & $\begin{array}{l}\text { B3LYP (calculated) } \\
\text { scaled (in lit.) }\end{array}$ & IR (int.) & Exp. IR & Exp. Raman & Vibrational assignments \\
\hline 281 & $271(267)$ & 8.1672 & - & 276 & Out of plane bend in $\mathrm{CH}_{2}-\mathrm{O}-\mathrm{CH}_{2}$ \\
\hline 644 & $620(635)$ & 4.7345 & 625 & - & $\tau(\mathrm{C}-\mathrm{O}-\mathrm{C}-\mathrm{C})$ \\
\hline 799 & 769 & 5.8498 & 765 & - & Twist $\mathrm{CH}_{2}$ \\
\hline 866 & 834 & 4.358 & 825 & - & Twist $\mathrm{CH}_{2}$ in whole \\
\hline 901 & $868(883)$ & 5.7608 & 865 & - & $\tau(\mathrm{C}-\mathrm{C}-\mathrm{C}-\mathrm{O})$ \\
\hline 941 & 906 & 22.7829 & 915 & 913 & Twist $\mathrm{CH}_{2}$ in whole \\
\hline 959 & $924(934)$ & 17.9192 & 930 & - & Ring breathing \\
\hline 1046 & 1007 & 4.7743 & 995 & - & $\beta(\mathrm{C}-\mathrm{C}-\mathrm{H})+\beta(\mathrm{C}-\mathrm{O}-\mathrm{C})$ \\
\hline 1097 & $1056(1068)$ & 83.1142 & 1045 & 1071 & Ring deformation \\
\hline 1214 & 1169 & 6.4279 & 1175 & 1174 & $\beta(\mathrm{C}-\mathrm{C}-\mathrm{H})$ \\
\hline 1261 & $1214(1214)$ & 5.8725 & 1205 & - & Twist $\mathrm{CH}_{2}$ \\
\hline 1268 & 1221 & 5.1994 & 1220 & 1234 & Twist $\mathrm{CH}_{2}$ \\
\hline 1395 & 1343 & 4.7295 & 1335 & 1335 & $\beta(\mathrm{C}-\mathrm{C}-\mathrm{H})$ \\
\hline 1506 & $1450(1454)$ & 5.5918 & 1445 & 1452 & $\mathrm{~S}\left(\mathrm{CH}_{2}\right)$ \\
\hline 2958 & 2848 & 43.4017 & 2840 & - & $v(\mathrm{C}-\mathrm{H})$ \\
\hline 2964 & 2854 & 118.3793 & 2855 & - & $v(\mathrm{C}-\mathrm{H})$ \\
\hline 3052 & $2939(2936)$ & 24.963 & 2930 & 2938 & $\nu(\mathrm{C}-\mathrm{H})$ \\
\hline 3062 & 2949 & 40.015 & 2950 & - & $\nu(\mathrm{C}-\mathrm{H})$ \\
\hline 3082 & $2968(2968)$ & 19.4174 & 2965 & 2975 & $v(\mathrm{C}-\mathrm{H})$ \\
\hline 3098 & 2983 (2989) & 34.7534 & 2980 & - & $v(\mathrm{C}-\mathrm{H})$ \\
\hline 3110 & 2995 & 77.426 & 2990 & - & $v(\mathrm{C}-\mathrm{H})$ \\
\hline
\end{tabular}

3.2. Assignment of Fundamentals. Tetrahydrofuran has 13 atoms with 33 normal modes of vibration while amino tetrahydrofuran has 15 atoms with 39 normal modes of vibration. 1,2-Diamino tetrahydrofuran, 1,2,3-triamino tetrahydrofuran, and 1,2,3,4-tetra-amino tetrahydrofuran have 17, 19, and 21 atoms with 45, 51, and 57 normal modes of vibration, respectively. From our calculated data and experimental FTIR spectra, we observe similarities and differences between the experimental and the calculated frequencies by DFT/B3LYP method. Assignments are done using the animated view of normal mode description. A good agreement is found between the theoretical and experimental data. Here we are discussing only important modes. Vibrational frequencies, calculated for tetrahydrofuran and experimental frequencies (FTIR), have been compared in Table 2 . We are also discussing the assignments for tetrahydrofuran derivatives which are useful for the experimentalists in absence of its experimental data. 
TABLE 3: Vibrational assignments of amino tetrahydrofuran (modes having high IR intensity only) with B3LYP/6-311 G (d, p).

\begin{tabular}{lccc}
\hline $\begin{array}{l}\text { B3LYP } \\
\text { (calculated) } \\
\text { unscaled }\end{array}$ & $\begin{array}{c}\text { B3LYP } \\
\text { (calculated) } \\
\text { scaled }\end{array}$ & IR (int.) & Vibrational assignments \\
\hline 197 & 190 & 48.1062 & Rock NH$_{2}$ \\
378 & 364 & 16.1235 & Group $\mathrm{NH}_{2}$ bend from joint \\
778 & 749 & 174.8209 & Rock NH$H_{2}$ \\
877 & 845 & 23.6231 & $\beta(\mathrm{C}-\mathrm{C}-\mathrm{H})+\beta(\mathrm{C}-\mathrm{C}-\mathrm{C})$ \\
957 & 922 & 65.1906 & $\beta(\mathrm{C}-\mathrm{C}-\mathrm{H})$ \\
1067 & 1028 & 52.4498 & Ring deformation \\
1133 & 1091 & 73.4975 & $\beta(\mathrm{C}-\mathrm{C}-\mathrm{C})$ \\
1443 & 1390 & 25.3256 & $\beta(\mathrm{C}-\mathrm{C}-\mathrm{H})$ \\
1647 & 1586 & 38.9601 & $\mathrm{~S}(\mathrm{NH})$ \\
2971 & 2861 & 74.2781 & $\nu(\mathrm{C}-\mathrm{H})$ \\
2993 & 2882 & 62.1676 & $\nu(\mathrm{C}-\mathrm{H})$ \\
3023 & 2911 & 28.6539 & $\nu(\mathrm{C}-\mathrm{H})$ \\
3058 & 2945 & 64.6532 & $\nu(\mathrm{C}-\mathrm{H})$ \\
3095 & 2980 & 55.4994 & $\nu(\mathrm{C}-\mathrm{H})$ \\
3595 & 3462 & 0.4042 & $\nu(\mathrm{N}-\mathrm{H})$ \\
\hline
\end{tabular}

\subsection{Vibrational Modes Description}

3.3.1. $C-H$ Vibrations. We have seen in the literature that the $\mathrm{C}-\mathrm{H}$ stretching vibrations are usually observed in 2800$3200 \mathrm{~cm}^{-1}$ region. In the study of tetrahydrofuran, the $(\mathrm{C}-\mathrm{H})$ functional group is present at 2848, 2854, 2939, 2949, 2968, 2983 , and $2995 \mathrm{~cm}^{-1}$ in calculated spectra which is in good agreement with the experimental data as given in Table 2 . In vibrational assignments, the $\mathrm{C}-\mathrm{H}$ stretching vibrations are in the same range for all derivatives of tetrahydrofuran listed in Tables 3, 4, 5, and 6 .

3.3.2. $\mathrm{N}-\mathrm{H}$ Vibrations. There is no $\mathrm{NH}_{2}$ group added to tetrahydrofuran but they are presented in all derivatives of tetrahydrofuran. The $\mathrm{N}-\mathrm{H}$ stretching vibrations are normally viewed in the region $3300-3600 \mathrm{~cm}^{-1}$. For amino tetrahydrofuran, the N-H stretching vibration is calculated at $3462 \mathrm{~cm}^{-1}$ while it is $3446 \mathrm{~cm}^{-1}$ for 1,2-diamino tetrahydrofuran. A strong scissoring vibration of $\mathrm{H}-\mathrm{N}-\mathrm{H}$ is found at 1586 and $1584 \mathrm{~cm}^{-1}$ for amino tetrahydrofuran and 1,2-diamino tetrahydrofuran, respectively. In case of 1,2,3-triamino tetrahydrofuran and 1,2,3,4-tetra-amino tetrahydrofuran, the $\mathrm{N}-\mathrm{H}$ vibration is at 3447 and $3354 \mathrm{~cm}^{-1}$ in calculated spectra. There are also strong scissoring vibrations at 1587 and $1588 \mathrm{~cm}^{-1}$ for 1,2,3-triamino tetrahydrofuran and 1,2,3,4-tetra-amino tetrahydrofuran. Some strong rocking and twisting vibrations of $\mathrm{NH}_{2}$ are also seen in the assignment of all derivatives of tetrahydrofuran. We see that scissoring modes in THF are lower than all the derivatives of THF. This is due to the addition of amino group (charge transfer) to THF molecule. The interpretation of vibrational spectra of THF is in good agreement with the literature [18] as given in Table 2.
TABLE 4: Vibrational assignments of 1,2-diamino tetrahydrofuran (modes having high IR intensity only) with B3LYP/6-311 G (d, p).

\begin{tabular}{|c|c|c|c|}
\hline $\begin{array}{l}\text { B3LYP } \\
\text { (calculated) } \\
\text { unscaled }\end{array}$ & $\begin{array}{c}\text { B3LYP } \\
\text { (calculated) } \\
\text { scaled }\end{array}$ & IR (int.) & $\begin{array}{l}\text { Vibrational } \\
\text { assignments }\end{array}$ \\
\hline 257 & 247 & 77.5282 & Rock $\mathrm{NH}_{2}$ \\
\hline 424 & 408 & 30.1483 & Twist $\mathrm{NH}_{2}$ \\
\hline 753 & 725 & 46.0965 & $\tau(\mathrm{C}-\mathrm{C}-\mathrm{C}-\mathrm{C})$ \\
\hline 859 & 827 & 83.126 & Rock $\mathrm{NH}_{2}$ \\
\hline 905 & 872 & 171.3772 & Rock $\mathrm{NH}_{2}$ \\
\hline 921 & 887 & 45.5585 & Rock $\mathrm{NH}_{2}$ \\
\hline 954 & 919 & 112.828 & Rock $\mathrm{NH}_{2}$ \\
\hline 1029 & 991 & 33.4007 & Twist $\mathrm{CH}_{2}$ \\
\hline 1068 & 1028 & 80.3998 & Ring deformation \\
\hline 1164 & 1121 & 20.3894 & $\begin{array}{c}\beta(\mathrm{C}-\mathrm{C}-\mathrm{H}) \text { in whole } \\
\text { molecule }\end{array}$ \\
\hline 1446 & 1392 & 14.2825 & $\beta(\mathrm{C}-\mathrm{C}-\mathrm{H})$ \\
\hline 1645 & 1584 & 63.057 & $\mathrm{~S}\left(\mathrm{NH}_{2}\right)$ \\
\hline 1669 & 1607 & 31.4909 & $\mathrm{~S}\left(\mathrm{NH}_{2}\right)$ \\
\hline 2974 & 2864 & 55.4405 & $\nu(\mathrm{C}-\mathrm{H})$ \\
\hline 3010 & 2899 & 61.7424 & $\nu(\mathrm{C}-\mathrm{H})$ \\
\hline 3038 & 2926 & 34.5478 & $\nu(\mathrm{C}-\mathrm{H})$ \\
\hline 3044 & 2931 & 53.5102 & $v(\mathrm{C}-\mathrm{H})$ \\
\hline 3074 & 2960 & 46.2551 & $\nu(\mathrm{C}-\mathrm{H})$ \\
\hline 3090 & 2976 & 46.8808 & $\nu(\mathrm{C}-\mathrm{H})$ \\
\hline 3578 & 3446 & 3.4588 & $v(\mathrm{~N}-\mathrm{H})$ \\
\hline
\end{tabular}

3.3.3. Other Modes of Vibration. In tetrahydrofuran, a ring deformation mode is calculated at $1056 \mathrm{~cm}^{-1}$ which is in good agreement with experimental data, that is, $1055 \mathrm{~cm}^{-1}$, while in all derivatives of tetrahydrofuran (except the last one) ring deformation mode is at 1028,1028 , and $1036 \mathrm{~cm}^{-1}$ having appropriate IR intensity. As expected, torsion modes along with wagging modes appear in the lower frequency range. For tetrahydrofuran, strong torsion mode of $\mathrm{C}-\mathrm{O}-\mathrm{C}-\mathrm{C}$ is at $628 \mathrm{~cm}^{-1}$ in calculated spectrum which matches well with the experimental one, that is, $625 \mathrm{~cm}^{-1}$, while strong torsion modes of C-C-C-C are at 725 and $474 \mathrm{~cm}^{-1}$ in calculated spectrum for 1,2-di-ATHF and 1,2,3-tri-ATHF, respectively. A very strong stretching vibration of $\mathrm{C}-\mathrm{O}$ is found at $981 \mathrm{~cm}^{-1}$ while there is also a strong torsion mode of $\mathrm{C}-\mathrm{C}-\mathrm{C}-\mathrm{O}$ at $731 \mathrm{~cm}^{-1}$ in calculated spectra for 1,2,3,4-tetra-ATHF. There are some frequencies in lower region having appreciable IR intensity. Furthermore, the study of low frequency vibrations is of great significance, because it gives information on weak intermolecular interactions, which take place in enzyme reactions [19]. Knowledge of low frequency mode is also essential for the interpretation of the effect of electromagnetic radiation on biological systems [20]. The aim of vibrational analysis is to acquire direct information on lower and higher frequency vibrations of such THF and its derivatives. No experimental FTIR spectrum is available for comparison of derivatives of THF so it will provide a suitable path for experimental researchers. 
TABLE 5: Vibrational assignments of 1,2,3-triamino tetrahydrofuran (modes having high IR intensity only) with B3LYP/6-311 G (d, p).

\begin{tabular}{|c|c|c|c|}
\hline $\begin{array}{l}\text { B3LYP } \\
\text { (calculated) } \\
\text { unscaled }\end{array}$ & $\begin{array}{c}\text { B3LYP } \\
\text { (calculated) } \\
\text { scaled }\end{array}$ & IR (int.) & Vibrational assignments \\
\hline 187 & 180 & 38.0082 & Twist $\mathrm{NH}_{2}$ \\
\hline 274 & 264 & 29.2943 & Twist $\mathrm{NH}_{2}$ \\
\hline 324 & 312 & 23.6603 & Twist $\mathrm{NH}_{2}$ \\
\hline 376 & 362 & 23.1528 & Twist $\mathrm{NH}_{2}$ \\
\hline 492 & 474 & 18.1122 & $\tau(\mathrm{C}-\mathrm{C}-\mathrm{C}-\mathrm{C})$ \\
\hline 635 & 612 & 213.3144 & Rock $\mathrm{NH}_{2}$ \\
\hline 832 & 801 & 68.3448 & Rock $\mathrm{NH}_{2}$ \\
\hline 859 & 827 & 130.0253 & Rock $\mathrm{NH}_{2}$ \\
\hline 936 & 901 & 46.5701 & Ring deformation \\
\hline 994 & 957 & 65.805 & $\beta(C-C-C)$ \\
\hline 1026 & 988 & 47.4846 & $\beta(\mathrm{C}-\mathrm{C}-\mathrm{H})$ \\
\hline 1076 & 1036 & 78.3665 & Ring deformation \\
\hline 1132 & 1090 & 33.1727 & $\beta(\mathrm{C}-\mathrm{C}-\mathrm{H})$ \\
\hline 1153 & 1110 & 30.0604 & $\beta(\mathrm{C}-\mathrm{C}-\mathrm{H})$ \\
\hline 1167 & 1124 & 48.7819 & $\beta(\mathrm{C}-\mathrm{C}-\mathrm{H})$ \\
\hline 1442 & 1389 & 21.4953 & $\beta(\mathrm{C}-\mathrm{C}-\mathrm{H})$ \\
\hline 1648 & 1587 & 47.0934 & $\mathrm{~S}\left(\mathrm{NH}_{2}\right)$ \\
\hline 1660 & 1599 & 29.1316 & $\mathrm{~S}\left(\mathrm{NH}_{2}\right)$ \\
\hline 2934 & 2825 & 37.6667 & $\nu(\mathrm{C}-\mathrm{H})$ \\
\hline 2950 & 2841 & 86.3504 & $v(\mathrm{C}-\mathrm{H})$ \\
\hline 3006 & 2895 & 115.4219 & $\nu(\mathrm{C}-\mathrm{H})$ \\
\hline 3057 & 2944 & 47.6972 & $v(\mathrm{C}-\mathrm{H})$ \\
\hline 3579 & 3447 & 5.6057 & $\nu(\mathrm{N}-\mathrm{H})$ \\
\hline
\end{tabular}

3.4. Electrical, Optical, Dipole Moment and Thermodynamical Properties. Frontier orbital energy gap, that is, the gap between HOMO and LUMO, shows the interaction of that molecule with other species. Frontier orbital energy gap helps to differentiate the chemical reactivity of the molecules. In case of tetrahydrofuran and its derivatives, frontier orbital energy gap is $7.9402,6.9066,6.8312,6.4991$, and $6.8870 \mathrm{eV}$, respectively, and is given in Table 7 . So it can be concluded that 1,2,3-triamino tetrahydrofuran is the most reactive compound among all. The pictures of HOMO, LUMO, and electrostatic potential (MESP) for tetrahydrofuran and its derivatives are shown in Figure 2.

Dipole moment $(\mu)$, polarizability $\langle\alpha\rangle$, and total first static hyperpolarizability $\beta[21,22]$ can be expressed in terms of $x, y, z$ components and are given by the following equations:

$$
\begin{aligned}
\mu & =\left(\mu_{x}^{2}+\mu_{y}^{2}+\mu_{z}^{2}\right)^{1 / 2}, \\
\langle\alpha\rangle= & \frac{1}{3}\left[\alpha_{x x}+\alpha_{y y}+\alpha_{z z}\right], \\
\beta_{\text {Total }}= & \left(\beta_{x}^{2}+\beta_{y}^{2}+\beta_{z}^{2}\right)^{1 / 2} \\
= & {\left[\left(\beta_{x x x}+\beta_{x y y}+\beta_{x z z}\right)^{2}\right.} \\
& +\left(\beta_{y y y}+\beta_{y x x}+\beta_{y z z}\right)^{2} \\
& \left.+\left(\beta_{z z z}+\beta_{z x x}+\beta_{z y y}\right)^{2}\right]^{1 / 2} .
\end{aligned}
$$

\begin{tabular}{|c|c|c|c|}
\hline $\begin{array}{l}\text { B3LYP } \\
\text { (calculated) } \\
\text { unscaled }\end{array}$ & $\begin{array}{c}\text { B3LYP } \\
\text { (calculated) } \\
\text { scaled }\end{array}$ & IR (int.) & Vibrational assignments \\
\hline 260 & 250 & 43.2432 & Twist $\mathrm{NH}_{2}$ \\
\hline 301 & 290 & 22.3762 & Twist $\mathrm{NH}_{2}$ \\
\hline 347 & 334 & 25.9587 & Rock $\mathrm{NH}_{2}$ \\
\hline 366 & 352 & 21.3354 & Rock $\mathrm{NH}_{2}$ \\
\hline 426 & 410 & 18.1696 & Twist $\mathrm{NH}_{2}$ \\
\hline 513 & 494 & 54.7952 & Torsion in whole molecule \\
\hline 593 & 571 & 38.3343 & $\tau(\mathrm{C}-\mathrm{C}-\mathrm{O}-\mathrm{C})$ \\
\hline 663 & 638 & 28.8211 & $\tau(\mathrm{C}-\mathrm{C}-\mathrm{C}-\mathrm{C})$ \\
\hline 759 & 731 & 56.9814 & $\tau(\mathrm{C}-\mathrm{C}-\mathrm{C}-\mathrm{O})$ \\
\hline 802 & 772 & 106.1627 & Rock $\mathrm{NH}_{2}$ \\
\hline 850 & 819 & 60.9417 & Rock $\mathrm{NH}_{2}$ \\
\hline 865 & 833 & 73.3106 & Twist $\mathrm{NH}_{2}$ in whole places \\
\hline 881 & 848 & 335.8006 & Twist $\mathrm{NH}_{2}$ \\
\hline 902 & 869 & 149.2133 & Rock $\mathrm{NH}_{2}$ \\
\hline 944 & 909 & 85.627 & Rock $\mathrm{NH}_{2}$ \\
\hline 972 & 936 & 31.7804 & $\beta(\mathrm{C}-\mathrm{C}-\mathrm{C})+$ Twist $\mathrm{NH}_{2}$ \\
\hline 1019 & 981 & 132.2283 & $v(\mathrm{C}-\mathrm{O})$ \\
\hline 1097 & 1056 & 16.8407 & Twist $\mathrm{NH}_{2}$ \\
\hline 1167 & 1124 & 27.6511 & Bending in whole molecule \\
\hline 1183 & 1139 & 25.494 & $\beta(\mathrm{C}-\mathrm{C}-\mathrm{H})$ \\
\hline 1441 & 1388 & 19.585 & $\beta(\mathrm{C}-\mathrm{C}-\mathrm{H})$ \\
\hline 1635 & 1575 & 55.77 & $\mathrm{~S}\left(\mathrm{NH}_{2}\right)$ \\
\hline 1649 & 1588 & 56.9828 & $\mathrm{~S}\left(\mathrm{NH}_{2}\right)$ \\
\hline 2946 & 2837 & 39.5477 & $\nu(\mathrm{C}-\mathrm{H})$ \\
\hline 2984 & 2874 & 58.3297 & $\nu(\mathrm{C}-\mathrm{H})$ \\
\hline 3033 & 2921 & 82.6875 & $\nu(\mathrm{C}-\mathrm{H})$ \\
\hline 3483 & 3354 & 19.1928 & $v(\mathrm{~N}-\mathrm{H})$ \\
\hline 3585 & 3452 & 11.9623 & $\nu(\mathrm{N}-\mathrm{H})$ \\
\hline
\end{tabular}

TABLE 6: Vibrational assignments of 1,2,3,4-tetra-amino tetrahydrofuran (modes having high IR intensity only) with B3LYP/6-311 G (d, p).

The $\beta$ components of Gaussian output are reported in atomic units.

Where 1 a.u. $=8.3693 * 10^{-33}$ e.s.u., the calculated dipole moments for tetrahydrofuran and its derivatives are 1.585 , $2.855,1.667,4.022$, and 1.743 Debye, respectively. So, 1,2,3triamino tetrahydrofuran is a better solvent among them all. A greater contribution of $\alpha_{y y}$ is seen in THF, amino THF, and 1,2,3-triamino THF while $\alpha_{z z}$ is seen in 1,2-diamino THF and $\alpha_{x x}$ in 1,2,3,4-tetra-amino THF. For THF and 1,2,3-triamino THF, molecules are elongated more towards $Y$ direction and more contracted in the $X$ direction while amino THF molecule is elongated more towards $Y$ direction and more contracted in the $X$ direction. For 1,2-diamino THF, molecule is elongated more towards $Z$ direction and more contracted in the $X$ direction while 1,2,3,4-tetra-amino THF molecule is elongated more towards $X$ direction and more contracted in the $Y$ direction. It is seen that the components $\beta_{x x z}, \beta_{x x y}$, $\beta_{y y y}, \beta_{y y y}$, and $\beta_{x x x}$ contribute lager part of hyperpolarizability from THF to 1,2,3,4-tetra-amino THF. This shows that 
TABLE 7: Lowest energy, HOMO-LUMO gap (frontier orbital energy gap), and dipole moment of tetrahydrofuran and its derivatives by B3LYP/6-311 G (d, p) method.

\begin{tabular}{lccccc}
\hline Parameters & THF & Amino THF & 1,2 -Diamino THF & 1,2,3-Triamino THF & $1,2,3,4$-Tetra-amino THF \\
\hline Energy (in au) & -232.5134 & -287.8832 & -343.2555 & -398.6109 & -453.9997 \\
Dipole moment (in Debye) & 1.585 & 2.855 & 1.667 & 4.022 & 1.743 \\
HOMO & -0.25509 & -0.23322 & -0.22235 & -0.21917 & -0.22375 \\
LUMO & 0.03683 & 0.02070 & 0.02880 & 0.01977 & 0.02945 \\
Frontier orbital energy gap (eV) & 7.9402 & 6.9066 & 6.8312 & 6.4991 & 6.8870 \\
\hline
\end{tabular}

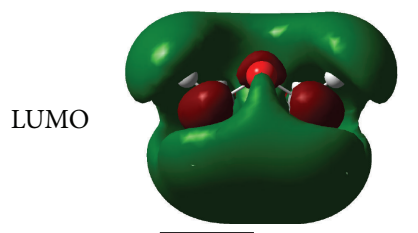

Frontier orbital
energy gap $(\mathrm{eV})$
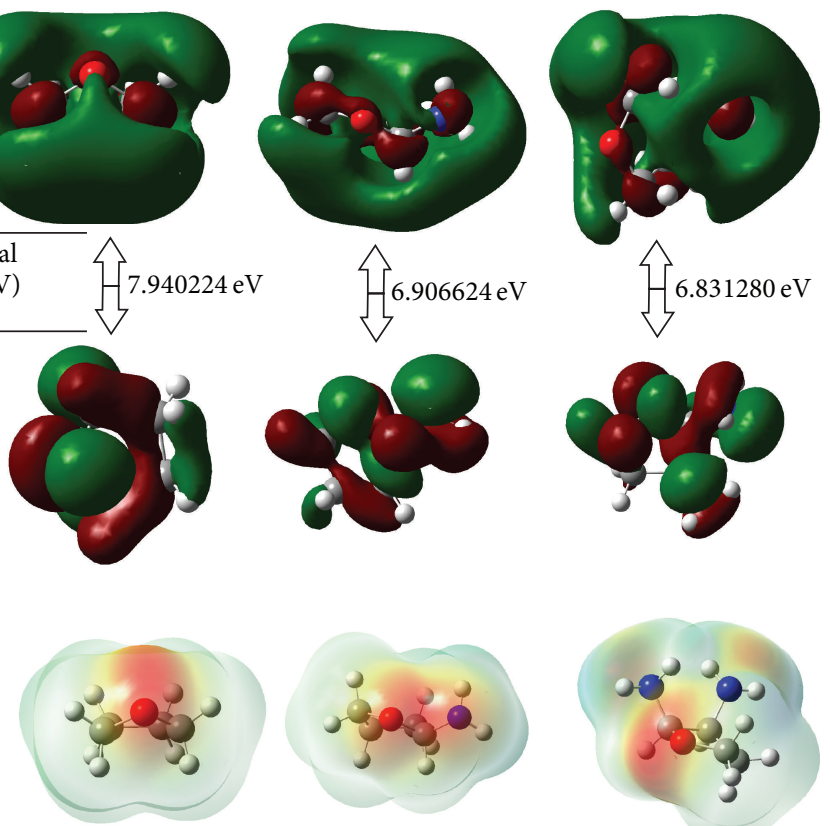

Tetrahydrofuran

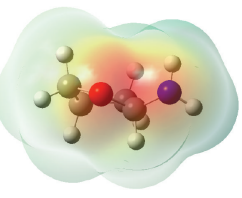

Amino tetrahydrofuran

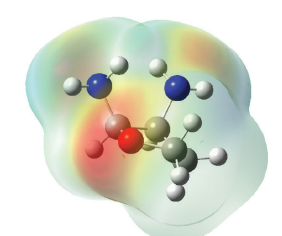

1,2-Diamino tetrahydrofuran

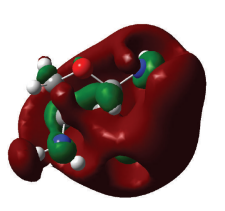

乌 $6.499168 \mathrm{eV}$
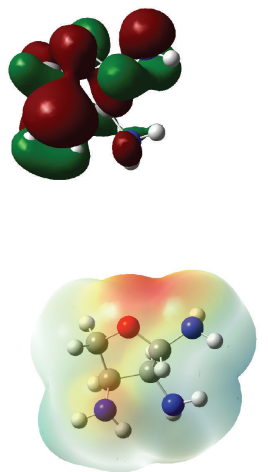

1,2,3-Triamino tetrahydrofuran
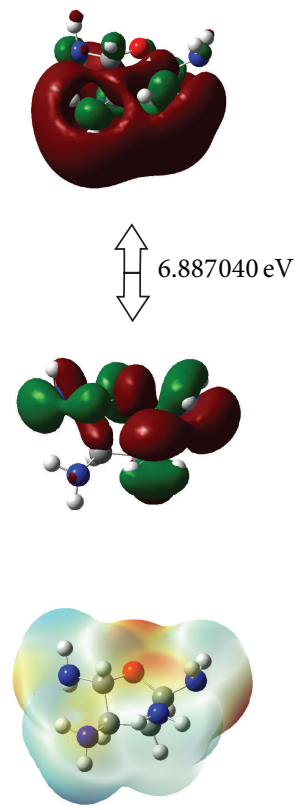

1,2,3,4-Tetra-amino tetrahydrofuran

FIgURE 2: Pictures of HOMO-LUMO and molecular electrostatic potential of tetrahydrofuran and its derivatives.

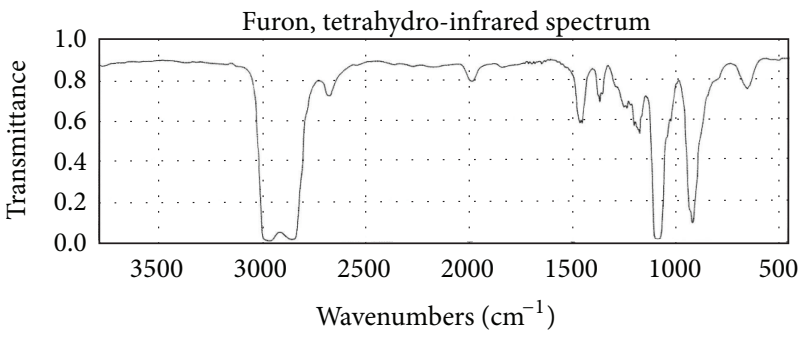

FIGURE 3: Experimental IR spectra of tetrahydrofuran.

$X Z$ and $X Y$ planes and $Y$ - and $X$-axes are more optically active in these directions. The values of hyperpolarizability indicate a possible use of these compounds in electrooptical applications.

Internal thermal energy $(E)$, constant volume heat capacity $C_{v}$, and entropy $S$, calculated at B3LYP/6-311 G (d, p) level, are listed in Table 9. We know that conduction band is almost empty at the room temperature, so electronic contribution in total energy is negligible. All the thermodynamic data supplies helpful information for the further study on the THF and its derivatives. They can be used to compute the other thermodynamic energies according to relationships of thermodynamic functions and estimate directions of chemical reactions according to the second law of thermodynamics in the thermochemical field. So thermodynamic properties show that vibrational motion plays an important role.

\subsection{Reactivity Descriptors}

3.5.1. Global Reactivity Descriptors. Global reactivity descriptors are described as

Energy band gap $=\left(\varepsilon_{\text {LUMO }}-\varepsilon_{\text {HOMO }}\right)$,

Electronegativity $(\chi)=-\frac{1}{2}\left(\varepsilon_{\mathrm{LUMO}}+\varepsilon_{\mathrm{HOMO}}\right)$,

Chemical potential $\mu=-\chi$,

Global hardness $\eta=\frac{1}{2}\left(\varepsilon_{\mathrm{LUMO}}-\varepsilon_{\mathrm{HOMO}}\right)$, 
TABLE 8: Polarizability and hyperpolarizability of tetrahydrofuran and its derivatives by B3LYP/6-311 G (d, p) methods.

\begin{tabular}{lccccc}
\hline Polarizability & THF & Amino THF & 1,2 -Diamino THF & $1,2,3$-Triamino THF & $1,2,3,4$-Tetra-amino THF \\
\hline$\alpha_{x x}$ & -29.2994 & -35.5422 & -41.5883 & -43.8040 & -55.7761 \\
$\alpha_{x y}$ & -0.0137 & 4.5742 & -2.1265 & 6.8303 & 0.1740 \\
$\alpha_{y y}$ & -34.8626 & -40.9807 & -41.9550 & -50.3155 & -50.3145 \\
$\alpha_{y z}$ & -0.7807 & -0.8029 & -0.1374 & 0.0764 & 2.3250 \\
$\alpha_{z z}$ & -31.4458 & -35.4849 & -43.4920 & -49.1301 & -53.4053 \\
$\alpha_{z x}$ & 0.0077 & 0.5506 & -0.9605 & -0.3221 & -2.4170 \\
$\alpha$ & 31.8692 & 37.3359 & 42.3451 & 47.7498 & 53.1653 \\
\hline & & & & -6.3842 & -6.7955 \\
$\beta_{x x x}$ & -0.0052 & 5.6681 & Hyperpolarizability & -4.6734 & -4.4365 \\
$\beta_{x x y}$ & -4.0970 & 6.2139 & -0.2912 & -3.2086 & -1.8247 \\
$\beta_{x y y}$ & 0.0298 & -1.6268 & -8.0690 & 14.4296 & -0.2671 \\
$\beta_{y y y}$ & -0.6535 & -0.2718 & 6.3043 & 2.4337 & -0.1471 \\
$\beta_{z z z}$ & -1.1489 & 1.5867 & 14.9291 & -0.5541 & -3.9772 \\
$\beta_{x x z}$ & -1.9217 & 1.5767 & 0.4088 & 6.3393 & -2.8358 \\
$\beta_{x z z}$ & -0.0222 & 3.9764 & -6.1872 & 2.7311 & -4.7413 \\
$\beta_{y z z}$ & -0.4033 & -1.2208 & 2.7638 & 6.3633 & 1.4539 \\
$\beta_{y y z}$ & 0.9213 & -0.3137 & -3.7949 & -3.0478 & -4.4281 \\
$\beta_{x y z}$ & 0.0193 & -1.1644 & -0.8388 & 32.0675 & 15.0620 \\
$\beta_{\text {total }}$ & 5.5840 & 9.7200 & -0.5408 & 11.4027 & \\
\hline & & & & \\
& & & &
\end{tabular}

TABLE 9: Calculated thermodynamic properties of tetrahydrofuran and its derivatives by B3LYP/6-311 G (d, p) methods.

\begin{tabular}{|c|c|c|c|c|c|}
\hline & THF & Amino THF & 1,2-Diamino THF & 1,2,3-Triamino THF & 1,2,3,4-Tetra-amino THF \\
\hline & \multicolumn{5}{|c|}{$E$ (thermal) $\left(\mathrm{kcalmol}^{-1}\right)$} \\
\hline Total & 75.553 & 87.449 & 99.560 & 110.546 & 122.799 \\
\hline Translational & 0.889 & 0.889 & 0.889 & 0.889 & 0.889 \\
\hline Rotational & 0.889 & 0.889 & 0.889 & 0.889 & 0.889 \\
\hline \multirow[t]{2}{*}{ Vibrational } & 73.776 & 85.672 & 97.783 & 108.769 & 121.022 \\
\hline & \multicolumn{5}{|c|}{$C_{V}\left(\mathrm{cal} \mathrm{K}^{-1} \mathrm{~mol}^{-1}\right)$} \\
\hline Total & 14.943 & 22.356 & 26.632 & 32.701 & 36.652 \\
\hline Translational & 2.981 & 2.981 & 2.981 & 2.981 & 2.981 \\
\hline Rotational & 2.981 & 2.981 & 2.981 & 2.981 & 2.981 \\
\hline \multirow[t]{2}{*}{ Vibrational } & 8.982 & 16.394 & 20.671 & 26.739 & 30.690 \\
\hline & \multicolumn{5}{|c|}{$S\left(\mathrm{cal} \mathrm{K}^{-1} \mathrm{~mol}^{-1}\right)$} \\
\hline Total & 67.259 & 78.055 & 81.513 & 88.746 & 91.737 \\
\hline Translational & 38.741 & 39.305 & 39.779 & 40.188 & 40.548 \\
\hline Rotational & 24.911 & 26.233 & 27.149 & 28.115 & 28.869 \\
\hline Vibrational & 3.607 & 12.517 & 14.584 & 20.443 & 22.320 \\
\hline
\end{tabular}

$$
\begin{gathered}
\text { Global softness }\left(S=\frac{1}{2 \eta}\right) \\
\text { Global electrophilicity index } \omega=\frac{\mu 2}{2 \eta}
\end{gathered}
$$

(see [23-27]). All these parameters for tetrahydrofuran and its derivatives have been listed in Table 6.

According to these parameters, the chemical reactivity varies with the structural configuration of molecules. Chemical hardness (softness) value of 1,2,3-amino THF is lesser (greater) among all the three molecules. Thus, 1,2,3-amino
THF is found to be most reactive among all, whereas THF configuration is less reactive. THF configuration possesses higher electronegativity while 1,2,3-amino THF possesses lower electrophilicity index among them all as given in Table 10. Correlations have been found between electrophilicity of various chemical compounds and reaction rates in biochemical systems.

3.6. Local Reactivity Descriptors. Fukui function (FF) provides information on the local site reactivity within the molecule and as such it provides a system for understanding of chemical reactions. These values correspond to the 
TABLE 10: Calculated $\varepsilon_{\text {HOMO }}, \varepsilon_{\text {LUMO }}$, energy band gap $\left(\varepsilon_{\text {LUMO }}-\varepsilon_{\text {HOMO }}\right)$, chemical potential $(\mu)$, electronegativity $(\chi)$, global hardness $(\eta)$, global softness $(S)$, and global electrophilicity index $(\omega)$ for tetrahydrofuran and its derivatives at B3LYP/6-311 G $(\mathrm{d}, \mathrm{p})$ level.

\begin{tabular}{lcccccccc}
\hline Compounds & $\varepsilon_{H}$ & $\varepsilon_{L}$ & $\varepsilon_{L}-\varepsilon_{H}$ & $\chi$ & $\mu$ & $\eta$ & $S$ \\
\hline THF & -0.25509 & 0.03683 & 0.29192 & 0.10913 & -0.10913 & 0.14596 & 3.425596054 & 0.0408 \\
1,2 THF & -0.23322 & 0.02070 & 0.25391 & 0.1011 & -0.1011 & 0.13398 & 3.7319 & 0.03814 \\
$1,2,3$-Amino THF & -0.22235 & 0.02880 & 0.25114 & 0.10323 & -0.10323 & 0.12631 & 3.95867 & 0.04218 \\
$1,2,3,4$ THF & -0.21917 & 0.01977 & 0.23893 & 0.09814 & -0.09814 & 0.13043 & 3.83347 & 0.03692 \\
Amino THF & -0.22375 & 0.02945 & 0.25319 & 0.10014 & -0.10014 & 0.1349 & 3.70645 & 0.03717 \\
\hline
\end{tabular}

TABLe 11: Fukui functions $\left(f_{k}^{+}, f_{k}^{-}\right)$, local softness $\left(s_{k}{ }^{+}, s_{k}{ }^{-}\right)$, and local electrophilicity indices $\left(\omega_{k}{ }^{+}, \omega_{k}{ }^{-}\right)$for selected atomic sites of CPPC, using Mulliken population analysis at B3LYP/6-311 G $(\mathrm{d}, \mathrm{p})$ level.

\begin{tabular}{|c|c|c|c|c|c|c|c|c|c|}
\hline THF & $\mathrm{M}$ & M- & $\mathrm{M}+$ & $f_{k}^{+}$ & $f_{k}^{-}$ & $s_{k}^{+}$ & $s_{k}^{-}$ & $\omega_{k}^{+}$ & $\omega_{k}^{-}$ \\
\hline $\mathrm{Cl}$ & 0.09218 & -0.13948 & 0.308091 & 0.231663 & 0.215911 & 0.793585 & 0.739625 & 0.009452 & 0.008809 \\
\hline $\mathrm{C} 2$ & 0.006981 & -0.24299 & 0.12914 & 0.249968 & 0.122159 & 0.85629 & 0.418468 & 0.010199 & 0.004984 \\
\hline C3 & 0.00709 & -0.24193 & 0.129566 & 0.249016 & 0.122476 & 0.853029 & 0.419554 & 0.01016 & 0.004997 \\
\hline $\mathrm{C} 4$ & 0.092228 & -0.13921 & 0.307449 & 0.231433 & 0.215221 & 0.792797 & 0.737261 & 0.009442 & 0.008781 \\
\hline $\mathrm{O} 13$ & -0.198474 & -0.23646 & 0.125765 & 0.037987 & 0.324239 & 0.130128 & 1.110713 & 0.00155 & 0.013229 \\
\hline Amino THF & $\mathrm{M}$ & M- & $\mathrm{M}+$ & $f_{k}^{+}$ & $f_{k}^{-}$ & $s_{k}^{+}$ & $s_{k}^{-}$ & $\omega_{k}^{+}$ & $\omega_{k}^{-}$ \\
\hline $\mathrm{C} 1$ & 0.122663 & 0.009106 & 0.241709 & 0.113557 & 0.119046 & 0.420893 & 0.441238 & 0.004221 & 0.004425 \\
\hline $\mathrm{C} 2$ & -0.008726 & -0.24682 & 0.114327 & 0.238093 & 0.123053 & 0.88248 & 0.45609 & 0.00885 & 0.004574 \\
\hline C3 & 0.010672 & -0.19419 & 0.113287 & 0.204865 & 0.102615 & 0.759322 & 0.380337 & 0.007615 & 0.003814 \\
\hline $\mathrm{C} 4$ & 0.089502 & -0.09679 & 0.248705 & 0.186288 & 0.159203 & 0.690467 & 0.590078 & 0.006924 & 0.005918 \\
\hline $\mathrm{O} 12$ & -0.203353 & -0.23584 & -0.04207 & 0.032482 & 0.161283 & 0.120393 & 0.597787 & 0.001207 & 0.005995 \\
\hline $\mathrm{N} 13$ & -0.010961 & -0.2358 & 0.323848 & 0.224837 & 0.334809 & 0.833347 & 1.240953 & 0.008357 & 0.012445 \\
\hline 1,2-Amino THF & $\mathrm{M}$ & M- & $\mathrm{M}+$ & $f_{k}^{+}$ & $f_{k}^{-}$ & $s_{k}^{+}$ & $s_{k}^{-}$ & $\omega_{k}^{+}$ & $\omega_{k}^{-}$ \\
\hline $\mathrm{C} 1$ & 0.080415 & -0.0421 & 0.22964 & 0.12251 & 0.149225 & 0.457195 & 0.556893 & 0.004673 & 0.005691 \\
\hline $\mathrm{C} 2$ & 0.004480 & -0.17372 & 0.087954 & 0.178204 & 0.083474 & 0.66504 & 0.311517 & 0.006797 & 0.003184 \\
\hline $\mathrm{C} 3$ & 0.035609 & -0.10002 & 0.115193 & 0.135632 & 0.079584 & 0.506165 & 0.297 & 0.005173 & 0.003035 \\
\hline $\mathrm{C} 4$ & 0.119975 & 0.005564 & 0.199748 & 0.114411 & 0.079773 & 0.42697 & 0.297705 & 0.004364 & 0.003043 \\
\hline O11 & -0.21865 & -0.24652 & -0.06071 & 0.02786 & 0.157941 & 0.103971 & 0.58942 & 0.001063 & 0.006024 \\
\hline N12 & -0.00822 & -0.16639 & 0.232471 & 0.158162 & 0.240694 & 0.590245 & 0.898246 & 0.006032 & 0.00918 \\
\hline N15 & -0.01388 & -0.27714 & 0.195416 & 0.263249 & 0.209305 & 0.982419 & 0.781105 & 0.01004 & 0.007983 \\
\hline 1,2,3-Amino THF & $\mathrm{M}$ & M- & $\mathrm{M}+$ & $f_{k}^{+}$ & $f_{k}^{-}$ & $s_{k}^{+}$ & $s_{k}^{-}$ & $\omega_{k}^{+}$ & $\omega_{k}^{-}$ \\
\hline $\mathrm{Cl}$ & 0.115624 & 0.073205 & 0.190554 & 0.042419 & 0.07493 & 0.167923 & 0.296623 & 0.001789 & 0.003161 \\
\hline $\mathrm{C} 2$ & 0.022828 & -0.08061 & 0.076666 & 0.103439 & 0.053838 & 0.409481 & 0.213127 & 0.004363 & 0.002271 \\
\hline $\mathrm{C} 3$ & 0.025129 & -0.0762 & 0.118366 & 0.101328 & 0.093237 & 0.401124 & 0.369095 & 0.004274 & 0.003933 \\
\hline $\mathrm{C} 4$ & 0.078038 & -0.01158 & 0.206247 & 0.089616 & 0.128209 & 0.35476 & 0.507537 & 0.00378 & 0.005408 \\
\hline $\mathrm{O} 10$ & -0.20327 & -0.22649 & -0.09324 & 0.023211 & 0.110038 & 0.091885 & 0.435604 & 0.000979 & 0.004641 \\
\hline N11 & -0.00094 & -0.20016 & 0.211528 & 0.19922 & 0.212469 & 0.788646 & 0.841095 & 0.008403 & 0.008962 \\
\hline N14 & -0.00158 & -0.3101 & 0.089629 & 0.308517 & 0.091209 & 1.221317 & 0.361066 & 0.013013 & 0.003847 \\
\hline N17 & -0.03592 & -0.16821 & 0.20016 & 0.132288 & 0.236083 & 0.523685 & 0.934575 & 0.00558 & 0.009958 \\
\hline 1,2,3,4-Amino THF & $\mathrm{M}$ & M- & $\mathrm{M}+$ & $f_{k}^{+}$ & $f_{k}^{-}$ & $s_{k}^{+}$ & $s_{k}^{-}$ & $\omega_{k}^{+}$ & $\omega_{k}^{-}$ \\
\hline $\mathrm{Cl}$ & 0.108686 & 0.070775 & 0.163507 & 0.037911 & 0.054821 & 0.145331 & 0.210155 & 0.0014 & 0.002024 \\
\hline $\mathrm{C} 2$ & 0.030688 & -0.08776 & 0.063705 & 0.118443 & 0.033017 & 0.454048 & 0.12657 & 0.004373 & 0.001219 \\
\hline C3 & 0.028906 & -0.0894 & 0.100662 & 0.118308 & 0.071756 & 0.45353 & 0.275074 & 0.004368 & 0.002649 \\
\hline $\mathrm{C} 4$ & 0.110441 & 0.02905 & 0.179846 & 0.081391 & 0.069405 & 0.31201 & 0.266062 & 0.003005 & 0.002562 \\
\hline O9 & -0.233907 & -0.2548 & -0.12637 & 0.020888 & 0.107535 & 0.080074 & 0.412232 & 0.000771 & 0.00397 \\
\hline N10 & -0.024483 & -0.11068 & 0.209354 & 0.086201 & 0.233837 & 0.330449 & 0.896407 & 0.003183 & 0.008633 \\
\hline N13 & -0.023684 & -0.16618 & 0.165895 & 0.142499 & 0.189579 & 0.546266 & 0.726745 & 0.005261 & 0.006999 \\
\hline N16 & 0.004591 & -0.24299 & 0.065478 & 0.24758 & 0.060887 & 0.949091 & 0.233408 & 0.009141 & 0.002248 \\
\hline N19 & -0.001198 & -0.14799 & 0.177963 & 0.146794 & 0.179161 & 0.56273 & 0.686808 & 0.00542 & 0.006615 \\
\hline
\end{tabular}


qualitative descriptors of reactivity of different atoms in the molecule. A study by Ayers and Parr [27] has shown that FF is larger when attacked by soft reagents and in places where the FF is smaller when attacked by hard reagents. Fukui functions for electrophilic and nucleophilic attacks have been made with the basis of B3LYP/6-311 G (d, p) level of theory. With the help of Mulliken atomic charges of cationic and anionic states, local Fukui functions $\left(f_{k}^{+}, f_{k}^{-}\right)$, local softness values $\left(s_{k}{ }^{+}, s_{k}{ }^{-}\right)$, and local electrophilicity indices $\left(\omega_{k}{ }^{+}, \omega_{k}{ }^{-}\right)$have been calculated using the following equation:

$$
\begin{aligned}
& f_{k}^{+}=[q(N+1)-q(N)] \quad \text { for nucleophilic attack } \\
& f_{k}^{-}=[q(N)-q(N-1)] \quad \text { for electrophilic attack } \\
& f_{k}{ }^{0}=\frac{1}{2}[q(N+1)+q(N-1)] \quad \text { for radical attack. }
\end{aligned}
$$

Local softness values and electrophilicity indices are calculated using

$$
\begin{array}{cc}
s_{k}^{+}=S f_{k}^{+}, & s_{k}^{-}=S f_{k}^{-} \\
{\omega_{k}^{+}}^{+}=\omega f_{k}^{+}, & {\omega_{k}^{-}}^{-}=\omega f_{k}^{-},
\end{array}
$$

where + and - signs show nucleophilic and electrophilic attack, respectively.

Fukui functions, local softness values, and local electrophilicity indices for selected atomic sites in tetrahydrofuran and its derivatives have been listed in Tables 7 and 8. For amino hydrofuran, the maximum value for local nucleophilic reactivity descriptors $\left(f_{k}{ }^{-}, s_{k}{ }^{-}, \omega_{k}{ }^{-}\right)$at N13 indicates that this site is more prone to electrophilic attack. But in comparison with N16 of 1,2,3,4-tetra-amino hydrofuran it is found that the N16 of 1,2,3,4-tetra-amino hydrofuran has lower affinity towards electrophile as given in Table 11. This situation changes because of change of position of the nitrogen of 1,2,3,4-tetra-amino hydrofuran, and hence the charge density around N16 decreased.

\section{Conclusions}

All calculated wave numbers are real in nature for all the molecules and thus all the compounds are stable. We have done density functional calculations on tetrahydrofuran and its derivatives. The calculated parameters (bond lengths and band angles) and wave numbers show a good agreement with the corresponding experimental data showing the strength of density functional calculations. Normal modes are discussed in detail with the help of Gauss view program. The chemical reactivity of molecules shows the supremacy of 1,2,3-triamino tetrahydrofuran over the remaining molecules. A possible use of these compounds in electrooptical applications is discussed with the help of hyperpolarizability. In addition, to assess the utility of global reactivity descriptors, the relationships between the reactivity and electrophilicity have been discussed. THF configuration possesses higher electronegativity while 1,2,3-amino THF possesses lower electrophilicity index among them all. Correlations have been found between electrophilicity of various chemical compounds and reaction rates in biochemical systems.

\section{Conflict of Interests}

The authors declare that there is no conflict of interests regarding the publication of this paper.

\section{Acknowledgments}

Abhishek Bajpai is thankful to University Grants Commissions, New Delhi, for its financial assistance. The corresponding author is also grateful to Professor Neeraj Misra for providing valuable suggestions.

\section{References}

[1] H. Müller, "Tetrahydrofuran," in Ullmann's Encyclopedia of Industrial Chemistry, Wiley-VCH, Weinheim, Germany, 2002.

[2] J. Swanston, “Thiophene," in Ullmann's Encyclopedia of Industrial Chemistry, Wiley-VCH, Weinheim, Germany, 2006.

[3] “Toxicological review of tetrahydrofuran," Tech. Rep. EPA/635/ R-11/006F, U.S. Environmental Protection Agency, Washington, DC, USA, 2012, http://www.epa.gov/iris.

[4] R. T. Morrison and R. N. Boyd, Organic Chemistry, Allyn and Bacon, Boston, Mass, USA, 2nd edition, 1972.

[5] D. Starr and R. M. Hixon, "Tetrahydrofuran," in Organic Syntheses Collective, vol. 2, p. 566, 1943.

[6] C. M. Cai, T. Zhang, R. Kumar, and C. E. Wyman, "THF co-solvent enhances hydrocarbon fuel precursor yields from lignocellulosic biomass," Green Chemistry, vol. 15, no. 11, pp. 3140-3145, 2013.

[7] A. Dwivedi, A. K. Pandey, and N. Misra, "Electronic structure, optical properties and vibrational analysis of 2-decenoic acid and its derivative by density functional theory," Spectroscopy, vol. 26, pp. 367-385, 2011.

[8] A. Dwivedi, A. K. Pandey, K. Raj, and N. Misra, "Comparative Study of Vibrational Spectra of Two Bioactive Natural Products Lupeol and Lupenone Using MM/QM Method," Spectroscopy: An International Journal, vol. 27, no. 3, pp. 155-166, 2012.

[9] A. K. Pandey, A. Bajpai, V. Baboo, and A. Dwivedi, "Structural, electronic, and vibrational properties of isoniazid and its derivative N-cyclopentylidenepyridine-4-carbohydrazide: a quantum chemical study," Journal of Th eoretical Chemistry, vol. 2014, Article ID 894175, 15 pages, 2014.

[10] "Tetrahydrofuran," Data from NIST Standard Reference Database 69: NIST Chemistry WebBook, 2005.

[11] A. D. Becke, "Density-functional thermochemistry. III. The role of exact exchange," The Journal of Chemical Physics, vol. 98, no. 7, pp. 5648-5652, 1993.

[12] C. Lee, W. Yang, and R. G. Parr, "Development of the ColleSalvetti correlation-energy formula into a functional of the electron density," Physical Review B, vol. 37, no. 2, pp. 785-789, 1988.

[13] P. Hohenberg and W. Kohn, "Inhomogeneous electron gas," Physical Review, vol. 136, pp. B864-B871, 1964.

[14] M. J. Frisch, G. W. Trucks, H. B. Schlegel et al., Gaussian 09, Revision D.01, Gaussian, Inc, Wallingford, Conn, USA, 2009.

[15] A. Frisch, A. B. Nelson, and A. J. Holder, Gauss View, Pittsburgh, $\mathrm{Pa}$, USA, 2005, http://www.gaussian.com/g_tech/gv5ref.htm.

[16] N. Sundaraganesan, H. Saleem, S. Mohan, M. Ramalingam, and V. Sethuraman, "FTIR, FT-Raman spectra and ab initio DFT vibrational analysis of 2-bromo-4-methyl-phenylamine," Spectrochimica Acta, vol. 62, no. 1-3, pp. 740-751, 2005. 
[17] P. K. Sahu, A. Chaudhari, and S.-L. Lee, "Theoretical investigation for the hydrogen bond interaction in THF-water complex," Chemical Physics Letters, vol. 386, no. 4, pp. 351-355, 2004.

[18] L. A. Evseeva and L. M. Sverdlov, "Analysis and interpretation of vibrational spectra of tetrahydrofuran and its deutreo derivatives," Soviet Physics Journal, vol. 11, no. 4, pp. 87-90, 1968.

[19] K.-C. Chou, "Biological functions of low-frequency vibrations (phonons). III. Helical structures and microenvironment," Biophysical Journal, vol. 45, no. 5, pp. 881-889, 1984.

[20] H. Frohlich, Biological Coherence and Response to External Stimuli, Springer, Berlin, Germany, 1988.

[21] D. A. Kleinman, "Nonlinear dielectric polarization in optical media," Physical Review B, vol. 126, no. 6, pp. 1977-1979, 1962.

[22] J. Pipek and P. G. Mezey, "A fast intrinsic localization procedure applicable for $a$ b in it i $o$ and semiempirical linear combination of atomic orbital wave functions," The Journal of Chemical Physics, vol. 90, no. 9, pp. 4916-4926, 1989.

[23] L. A. Flippin, D. W. Gallagher, and K. Jalali-Araghi, "A convenient method for the reduction of ozonides to alcohols with borane-dimethyl sulfide complex," The Journal of Organic Chemistry, vol. 54, no. 6, pp. 1430-1432, 1989.

[24] R. G. Parr, L. V. Szentpály, and S. Liu, "Electrophilicity index," Journal of the American Chemical Society, vol. 121, no. 9, pp. 1922-1924, 1999.

[25] P. K. Chattaraj and S. Giri, "Stability, reactivity, and aromaticity of compounds of a multivalent superatom," The Journal of Physical Chemistry A, vol. 111, no. 43, pp. 11116-11121, 2007.

[26] J. Padmanabhan, R. Parthasarathi, V. Subramanian, and P. K. Chattaraj, "Electrophilicity-based charge transfer descriptor," The Journal of Physical Chemistry A, vol. 111, no. 7, pp. 1358-1361, 2007.

[27] P. W. Ayers and R. G. Parr, "Variational principles for describing chemical reactions: the Fukui function and chemical hardness revisited," Journal of the American Chemical Society, vol. 122, no. 9, pp. 2010-2018, 2000. 

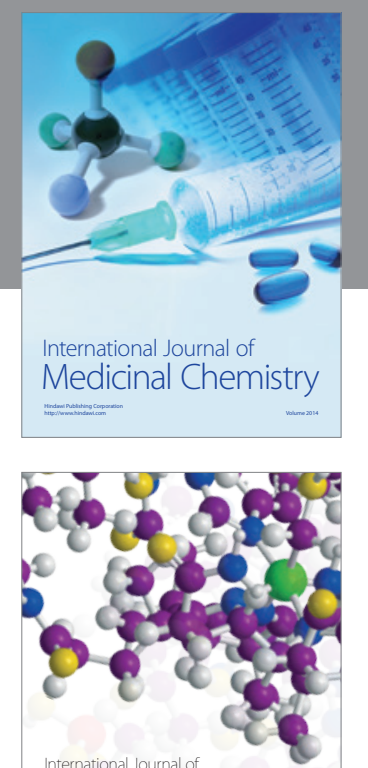

\section{Carbohydrate} Chemistry

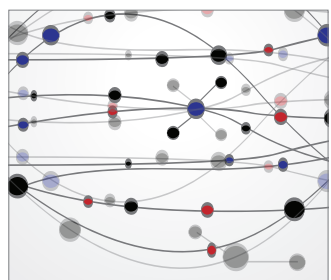

The Scientific World Journal
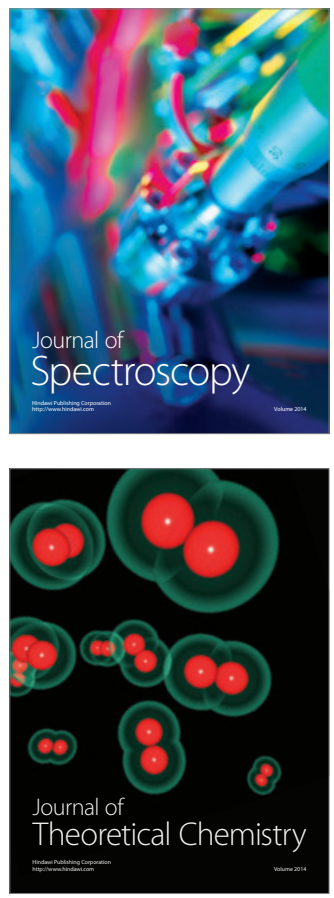
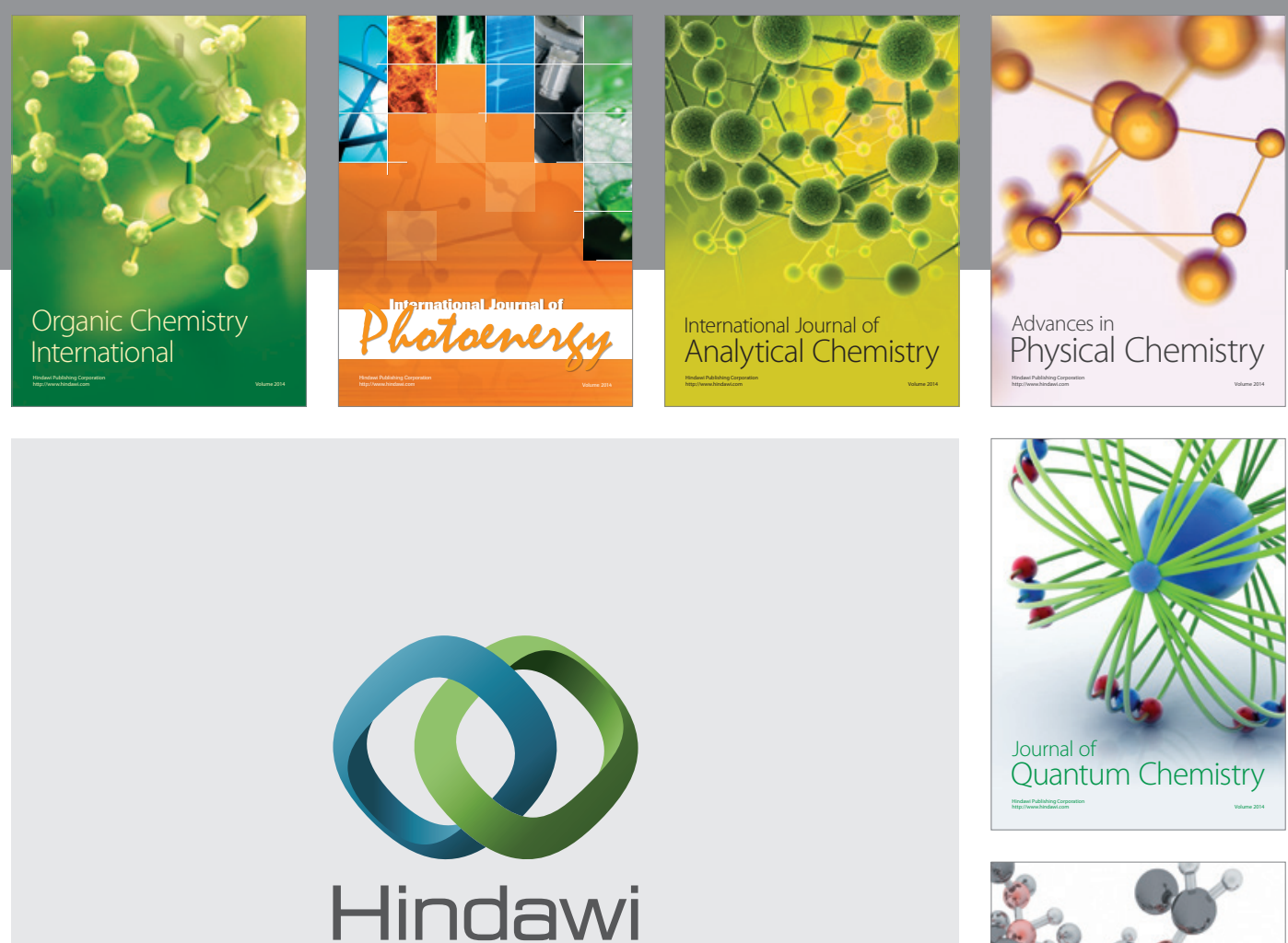

Submit your manuscripts at

http://www.hindawi.com

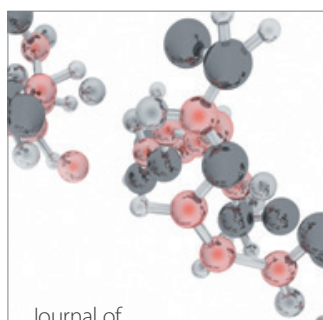

Analytical Methods

in Chemistry

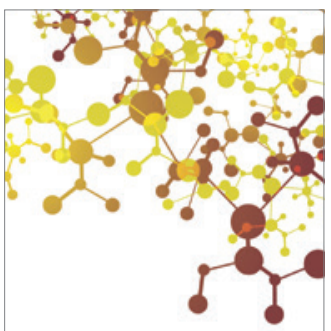

Journal of

Applied Chemistry

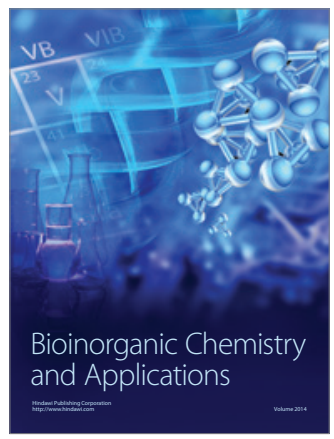

Inorganic Chemistry
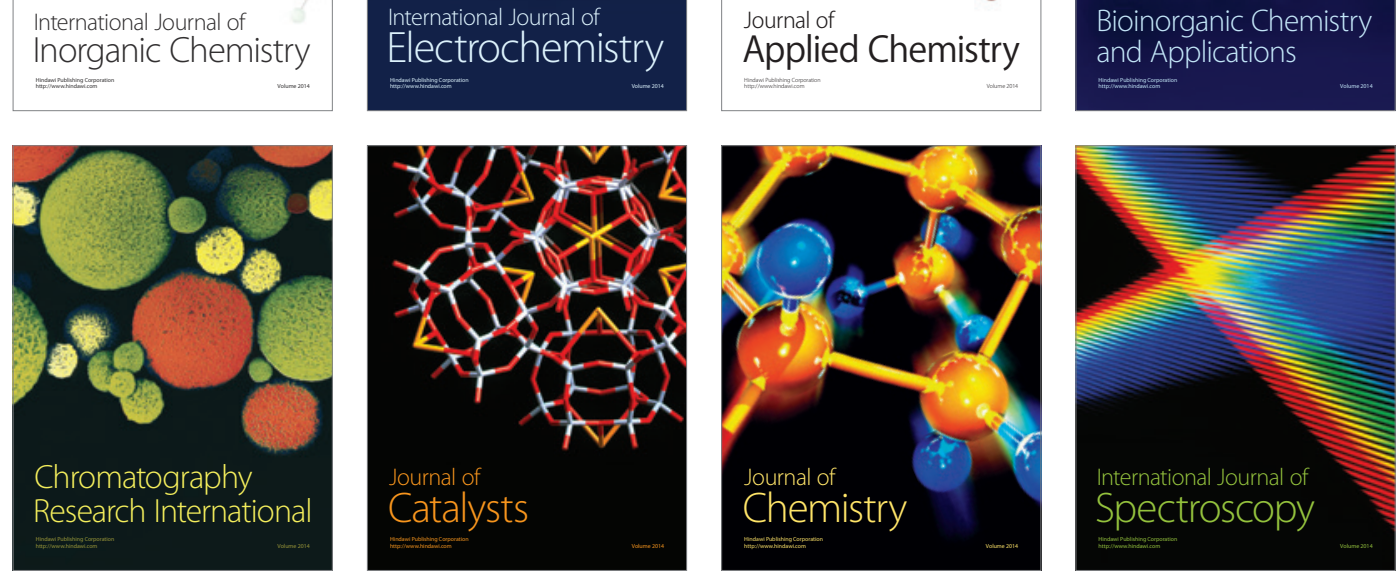